\title{
Françoise-Madeleine De Chaugy, Giovanna Francesca di Chantal. Memoria della vita e delle virtù
}

\section{Cecilia Rizza}

\section{(2) OpenEdition}

1 Journals

\section{Edizione digitale}

URL: http://journals.openedition.org/studifrancesi/6269

DOI: $10.4000 /$ studifrancesi.6269

ISSN: 2421-5856

\section{Editore}

Rosenberg \& Sellier

\section{Edizione cartacea}

Data di pubblicazione: 1 novembre 2010

Paginazione: 548

ISSN: 0039-2944

\section{Notizia bibliografica digitale}

Cecilia Rizza, «Françoise-Madeleine De Chaugy, Giovanna Francesca di Chantal. Memoria della vita e delle virtù», Studi Francesi [Online], 162 (LIV | III) | 2010, online dal 30 novembre 2015, consultato il 10 janvier 2021. URL: http://journals.openedition.org/studifrancesi/6269 ; DOI: https://doi.org/10.4000/ studifrancesi.6269

Questo documento è stato generato automaticamente il 10 janvier 2021.

\section{(c) $(1) \ominus$}

Studi Francesi è distribuita con Licenza Creative Commons Attribuzione - Non commerciale - Non opere derivate 4.0 Internazionale. 


\title{
Françoise-Madeleine De Chaugy, Giovanna Francesca di Chantal. Memoria della vita e delle virtù
}

\author{
Cecilia Rizza
}

\section{NOTIZIA}

FRANÇOISE MADELEINE DE CHAUGY, Giovanna Francesca di Chantal. Memoria della vita e delle virtù, traduzione dal francese a cura di Chiara RoLlA, Roma, Città Nuova Editrice, 2010.

1 Scritta all'indomani della morte nel 1641 della zia Jeanne-Françoise Frémiot de Chantal, questa vita della fondatrice dell'Ordine delle Visitandine sarà pubblicata in Francia soltanto nel xix secolo: una prima edizione a cura dell'Abbé Boulenger è del 1843 cui seguirà una seconda edizione nel 1853. Al 1856 risale la prima traduzione italiana. Bisognerà tuttavia attendere l'edizione francese del 1874 per avere una riproduzione completa e fedele del testo originale ed è questa versione, ormai definitiva dell'opera della Mère de Chaugy che è stata scelta per la traduzione italiana qui pubblicata. L'interesse di quest'opera va ben oltre il suo significato religioso in quanto offre una testimonianza di prima mano sulla vita della provincia francese nei primi decenni del xviı secolo e, grazie al rapporto privilegiato della Chantal con François de Sales, aiuta a meglio valutare l'opera di quel grande santo e la sua azione in un momento in cui la Chiesa Cattolica conosce in Francia un indubbio rinnovamento che vede tra i suoi principali protagonisti anche Saint Vincent de Paul. Sono anni difficili per la Chiesa di Roma per il persistente aspro conflitto con i Protestanti di cui il testo della Chantal offre numerose testimonianze, anche se, nella traduzione, alcuni passi giudicati troppo polemici sono stati soppressi dall'editore italiano. Né bisogna dimenticare quale importanza comincia ad assumere nella vita religiosa della Francia la pubblicazione nel 1641 dell'Augustinus di Giansenio. Di particolare interesse anche la lingua e lo stile della Chaugy in cui prevalgono freschezza e spontaneità al di là di ogni ricerca formale. 
2 La traduzione di Chiara Rolla si caratterizza per l'accurata fedeltà e la corretta interpretazione della lingua francese del Seicento cui danno giusto rilievo anche le numerose note con la citazione dei dizionari dell'epoca. Da segnalare, ancora nelle note, i puntuali riferimenti alla cultura e alle vicende storiche del tempo: essi permettono di riconoscere a quest'opera un interesse che va ben al di là del messaggio religioso, profondo e talvolta commovente, che ne costituisce pur sempre lo scopo principale. 